\title{
Níveis dos marcadores CEA e CA 19-9 no soro e no lavado peritoneal na avaliação do comprometimento linfonodal do carcinoma gástrico
}

Levels of CEA and CA 19-9 markers in sera and peritoneal wash and the evaluation of lymph node involvement in gastric carcinoma

Rafaella Falco Bruhn', René Crepaldi Filho², Rogério Tadeu Palma ${ }^{3}$ Lourdes Conceição Martins ${ }^{4}$, Carlos Alberto Nagashima ${ }^{3}$, Jaques Waisberg ${ }^{1,3}$

\begin{abstract}
Resumo
Introdução: A recidiva peritoneal precoce do carcinoma gástrico operado com intenção curativa constitui grande desafio para seu tratamento e prevenção. Objetivo: Analisar a relação entre os níveis do marcador tumoral CEA e CA 19-9 no sangue e no lavado peritoneal e o comprometimento linfonodal do carcinoma gástrico. Métodos: Foram estudados 46 doentes operados por carcinoma gástrico. Vinte e nove (63\%) eram do sexo masculino e 17 (37\%) do sexo feminino. Ressecção gástrica curativa foi realizada em 40 (91,3\%) e gastrectomia paliativa em 4 (8,7\%). A média de idade foi de 63,6 $\pm 11,7$ anos (31 a 91 anos). Após a indução anestésica, 0 sangue venoso periférico foi coletado de veia do membro superior para a determinação do nível sérico do CEA e CA 19-9. Após o término do procedimento operatório foram derramados $50 \mathrm{~mL}$ de solução fisiológica no fundo de saco de Douglas, aspirada alíquota para a determinação do nível no lavado peritoneal do CEA e CA 19-9. Resultados: Na comparação entre os doentes com e sem linfonodos comprometidos pelo carcinoma gástrico, os níveis de CEA sérico e no lavado peritoneal não apresentaram diferença significante ( $p=0,62$ e $p=0,13$, respectivamente). Não houve diferença significativa $(p=0,43)$ entre os níveis do CA 19-9 sérico e no lavado peritoneal nos enfermos com acometimento linfonodal pelo carcinoma gástrico. Na comparação entre os doentes com e sem linfonodos comprometidos, os níveis de CA 19-9 no lavado peritoneal foram significantemente maiores do que os do sangue periférico $(p=0,03)$. Conclusões: Nos doentes com carcinoma gástrico, o nível no lavado peritoneal do CA 19-9 pode sinalizar presença de infiltração linfonodal e constituir parâmetro para a indicação de tratamento adjuvante.
\end{abstract}

Palavras-chave: Neoplasias gástricas; marcadores biológicos de tumor; antígeno carcinoembrionário; antígeno CA-19-9; lavagem peritoneal; prognóstico.

\begin{abstract}
Introduction: Early peritoneal recurrence of gastric carcinoma following curative resection remains a great challenge in the treatment and prevention of this disease. Objective: The objective of this study was to analyze the relationship between levels of tumor markers CEA and CA 19-9 in sera and peritoneal wash, and lymph node involvement by gastric carcinoma. Methods: Forty-six patients operated by gastric carcinoma were analyzed. Twenty-nine (63\%) were males and $17(37 \%)$ females. Curative gastric resection was performed in 40 (91.3\%) and palliative gastrectomy was realized in 4 (8.7\%). Mean age was $63.6 \pm 11.7$ years (31 to 91 years). Peripheral venous blood samples were collected from the upper limb vein from both patient groups after anesthetic induction, in order to determine serum levels of CEA and CA 19-9. Following the operative procedure, $50 \mathrm{~mL}$ of physiologic solution was introduced into the bottom of the Douglas cull-de-sac and a portion aspirated to determine CEA and CA 19-9 levels in the peritoneal wash. Results: When we compared patients with or without lymph nodes compromised by gastric carcinoma, the serical and peritoneal levels of CEA did not show significant difference $(p=0.62$ and $p=0.13$, respectively). There was no significant difference ( $p=0.43$ ) between the serical and peritoneal levels of CA 19-9 in patients with lymph node involvement by gastric carcinoma. When we compared patients with and without lymph nodes compromised by gastric carcinoma, the CA $19-9$ levels in peritoneal wash were significantly higher $(p=0.03)$ than in peripheral blood. Conclusions: In patients with gastric carcinoma, the level of CA 19-9 in peritoneal wash can disclose the presence of lymph node involvement and it can indicate adjuvant treatment.
\end{abstract}

Keywords: Stomach neoplasms; tumor markers, biological; carcinoembryonic antigen; CA-19-9 antigen; peritoneal lavage; prognosis.

Recebido: 05/05/2008

Revisado: 09/08/2008

Aprovado: 11/08/2008

Disciplina de Cirurgia do Aparelho Digestivo, Faculdade de Medicina do ABC, Santo André (SP)

2 Hospital Israelita Albert Einstein, São Paulo (SP)

Hospital do Servidor Público Estadual Francisco Morato de Oliveira, São Paulo (SP)

4 Disciplina de Saúde Coletiva da Faculdade de Medicina do ABC, Santo André (SP)

Trabalho realizado no Serviço de Gastroenterologia do Hospital do Servidor Público Estadual Francisco Morato de Oliveira de São Paulo e no Laboratório de Oncologia da Faculdade de Medicina do ABC

Endereço para correspondência: Jaques Waisberg/Avenida Ibirapuera, 981, $6^{\circ}$ andar, sala 605 - Vila Clementino, CEP: 04029-000 - São Paulo (SP),

Telefone: (11) 5073-8854 -E-mail: jaqueswaisberg@uol.com.br 


\section{Introdução}

O carcinoma gástrico freqüentemente recidiva mesmo após operação potencialmente curativa em doentes sem evidências de doença metastática ${ }^{1,2}$ e é dificultoso constatar metástases linfonodais ou peritoneais antes ou mesmo durante a operação ${ }^{3-6}$.

O CEA $\mathrm{CE}^{7}$ entígeno encontrado nas células normais e neoplásicas da mucosa gástrica dos doentes portadores de câncer gástrico ${ }^{8}$. A principal diferença entre elas parece estar relacionada não só à maior capacidade de síntese pela célula neoplásica como também a alterações na dinâmica secretora do antígeno pela célula cancerosa, ${ }^{9}$. O CA 19-9 é mucina de alto peso molecular, cujos níveis plasmáticos elevados foram encontrados principalmente em doentes com neoplasias malignas pancreáticas e biliares e também em doentes com outras neoplasias gastrintestinais como os carcinomas colo-retal, gástrico e hepático ${ }^{11-15}$.

Irinoda et al. ${ }^{16}$ observaram que doentes com carcinoma gástrico e com níveis elevados de CEA no lavado peritoneal apresentaram maior incidência de metástases peritoneais e linfonodais. O prognóstico de doentes com níveis elevados de CEA no lavado peritoneal foi significativamente pior do que aqueles com níveis normais. O nível sérico préoperatório do CA 19-9 foi apontado como tendo significado prognóstico independente em doentes operados de carcinoma gástrico ${ }^{12}$. Como o CA 19-9 atua na adesão intercelular de moléculas, é concebível que a metástase oculta ou clínica seria mais intimamente relacionada com doentes com nível sérico aumentado do marcador.

Se fosse possível identificar, antes da operação, metástases linfonodais ou peritoneais em doentes com carcinoma gástrico avançado, esses enfermos poderiam ser tratados, durante a operação, com linfadenectomia radical ou com quimioterapia adjuvante intraperitoneal com doses elevadas de drogas antineoplásicas, para prevenir recidivas das metástases linfonodais ou peritoneais ${ }^{10,17-19}$.

O objetivo deste estudo foi analisar a relação entre os níveis do CEA e CA19-9 no sangue e no lavado peritoneal com o acometimento linfonodal no carcinoma gástrico.

Tabela 1 - Dados biodemográficos dos doentes submetidos ao tratamento cirúrgico do carcinoma gástrico

\begin{tabular}{lc}
\hline Variáveis & $\mathrm{N}=46$ \\
\hline Gênero & $29(63,0 \%)$ \\
\hline Masculino & $17(37,0 \%)$ \\
\hline Feminino & \\
\hline Etnia & $37(80,4 \%)$ \\
\hline Branca & $8(17,4 \%)$ \\
\hline Negra & $1(2,2 \%)$ \\
\hline Amarela & \\
\hline Idade (anos) & $63,6 \pm 11,7$ \\
\hline$\mu \pm$ dp & $31,0-91,0$ \\
\hline Mínimo - Máximo & \\
\hline
\end{tabular}

\section{Casuística e métodos}

Neste estudo, foram analisados 46 doentes portadores de carcinoma gástrico operados consecutivamente e com intenção curativa no Serviço de Gastroenterologia Cirúrgica do Hospital do Servidor Público Estadual Francisco Morato de Oliveira de São Paulo (HSPE-FMO), no período de julho 2003 a dezembro de 2005. Os ensaios laboratoriais foram realizados no laboratório do Setor de Oncologia da Faculdade de Medicina do ABC.

O projeto de pesquisa foi aprovado pelo Comitê de Ética em Pesquisa (CEP) e realizado de acordo com os padrões éticos aceitos pela Declaração de Helsinki da Associação Médica Mundial, adotado em 1964 e emendado em 1996.

As informações clínicas e morfológicas foram obtidas por consultas em prontuários hospitalares ou por entrevista com os doentes ou familiares nos retornos ambulatoriais.

Nas lesões localizadas na região antropilórica e com margem proximal, os doentes foram submetidos à gastrectomia subtotal. Nas lesões situadas no terço médio e proximal, os enfermos foram submetidos à gastrectomia total. Nesses casos, constatada macroscopicamente a penetração da lesão na serosa gástrica, os doentes foram submetidos à gastrectomia total ampliada, com extirpação do baço e da cauda do pâncreas. Em todas as resseções, o padrão de linfadenectomia foi D2 ${ }^{20}$.

O termo curativo foi utilizado para designar ausência de doença residual neoplásica macroscópica ao final da operação constatada pelo estadiamento pré-operatório e avaliação intra-operatória pelo cirurgião, e a presença de margens cirúrgicas livres no laudo do exame anatomopatológico da peça operatória extirpada.

Todos os doentes tiveram seu diagnóstico histológico de carcinoma gástrico confirmado pela revisão das lâminas coradas pelo método da hematoxilina-eosina (HE) e analisadas por patologista.

Nesse estudo foram considerados critérios de inclusão a presença de carcinoma gástrico confirmada pelo estudo histopatológico da lesão extirpada com intenção curativa ou paliativa. Foi considerado critério de exclusão os carcinomas localizados na região da cárdia e nos $3 \mathrm{~cm}$ acima e abaixo desta localização, e enfermos com manifestação clínica ou laboratorial de doença hepática.

Dos 46 doentes do estudo, 29 (63,0\%) eram do sexo masculino e 17 $(37,0 \%)$ do sexo feminino, resultando em uma proporção homem/mulher de 1,7:1. Em relação à raça, 37 (80,4\%) eram brancos, oito (17,4\%) negros e um (2,2\%) amarelo. A média de idade foi de 63,6 $\pm 11,7$ anos (31 a 91 anos) (Tabela 1).

Um grupo controle foi constituído para determinar os níveis do CEA e do CA 19-9 no lavado peritoneal que serviu como parâmetro normal. Esse controle foi formado por 18 doentes, sendo quatro $(22,2 \%)$ homens e 14 (77,8\%) mulheres. A média de idade foi de 45,6 $\pm 7,2$ anos. Todos apresentavam doença calculosa não complicada da vesícula biliar e colecistite crônica confirmada pelo resultado do laudo do exame anatomopatológico da peça operatória e foram operados por 
laparotomia ou por via laparoscópica. Todos os doentes deste grupo foram submetidos à endoscopia digestiva alta, que não revelou doença neoplásica gástrica. Nenhum doente desse grupo apresentava história de tabagismo.

Logo após a indução anestésica, o sangue venoso periférico foi coletado por punção percutânea com agulha acoplada à seringa de $10 \mathrm{~mL}$ de capacidade de veia do membro superior não dominante do doente, $\mathrm{e}$ colocado em frasco sem anticoagulante. O conteúdo foi encaminhado para a determinação dos níveis séricos do CEA e do CA 19-9.

Após o término do procedimento de gastrectomia subtotal, total ou paliativa nos doentes com neoplasia gástrica, e após a retirada da vesícula biliar nos enfermos do grupo controle, foi derramado no fundo de saco de Douglas, $50 \mathrm{~mL}$ de solução fisiológica aquecida à $37^{\circ} \mathrm{C}$; deste líquido foi aspirado o volume de $10 \mathrm{~mL}$ com seringa estéril, colocado em frasco sem anticoagulante e encaminhado para a determinação dos níveis do CEA e do CA 19-9 no lavado peritoneal. Outros $10 \mathrm{~mL}$ foram aspirados do líquido do lavado peritoneal, e esta amostra foi imediatamente centrifugada por cinco minutos a 1500 rotações por minuto (rpm). O sedimento dessa amostra foi transferido para uma lâmina de vidro, fixada em álcool a $99 \%$, corada por hematoxilina-eosina e examinada para a detecção de células neoplásicas por patologista experiente.

Os níveis de CEA e CA 19-9 foram determinados por imunoensaio de eletroquimioluminescência para determinação quantitativa in vitro em soro humanos em analisadores de imunoensaios ${ }^{21}$. Os resultados foram indicados em $\mathrm{ng} / \mathrm{mL}$.

Os valores dos níveis de CEA e de CA 19-9 no lavado peritoneal obtidos do grupo de doentes colecistectomizados e operados de carcinoma gástrico foram utilizados para a obtenção da curva ROC e estabelecimento dos níveis de corte (cut off) para os valores da sensibilidade e especificidade.

Em relação ao carcinoma gástrico foram estudadas as seguintes variáveis: operação realizada, localização da lesão, diâmetro da lesão gástrica no maior eixo, número de linfonodos extirpados, número de linfonodos acometidos pela neoplasia, nível sérico préoperatório do CEA e do CA 19-9, e nível do CEA e CA 19-9 no lavado peritoneal.

As variáveis qualitativas foram representadas por freqüência absoluta $(\mathrm{N})$ e relativa (porcentagem). Foram utilizados os seguintes modelos estatísticos: média aritmética e desvio padrão, teste do qui-quadrado e regressão logística múltipla, teste $t$ e teste de U-Mann-Whitney, teste de Kuskal-Wallis, teste não paramétrico de Spearman, teste do $t$ pareado, teste de Wilcoxon e teste de comparações múltiplas de Tukey. Para a análise de risco foi utilizada a regressão logística múltipla. Para as variáveis quantitativas, a homogeneidade das variâncias foi verificada pelo teste de Levene e a normalidade pelo teste de Kolmogorov-Smirnov. Em todos os testes, fixou-se em 5\% o nível para a rejeição da hipótese de nulidade (intervalo de confiância de 95\%) de acordo com os padrões correntes em estudos biológicos.

\section{Resultados}

O carcinoma gástrico primário estava localizado na região antropilórica em 28 (60,9\%) doentes e no corpo/fundo gástricos em 18 $(39,1 \%)$. Nos doentes desse estudo, a operação realizada foi gastrectomia subtotal em $26(56,5 \%)$ doentes, gastrectomia total ou gastrectomia total ampliada em $16(34,8 \%)$ enfermos e gastrectomia paliativa em quatro $(8,7 \%)$.

A média dos níveis do CEA e CA19-9 no lavado peritoneal dos enfermos do grupo controle foi, respectivamente, de 0,29 $\pm 0,7 \mathrm{ng} / \mathrm{mL}$ $(0,1$ a $3,1 \mathrm{ng} / \mathrm{mL})$ e de $4,53 \pm 2,8 \mathrm{U} / \mathrm{mL}(2,0$ a $9,93 \mathrm{U} / \mathrm{mL})$.

A média dos níveis do CEA e CA19-9 no pré-operatório dos doentes com carcinoma gástrico foi, respectivamente, de $3,63 \mathrm{ng} / \mathrm{m} / \mathrm{L}$ $\pm 15,21(0,2$ a $25 \mathrm{ng} / \mathrm{mL})$ e $17,5 \pm 24,8 \mathrm{U} / \mathrm{mL}(0,1$ a $101,3 \mathrm{U} / \mathrm{mL})$.

Nos doentes com carcinoma gástrico, a média do nível do CEA no lavado peritoneal foi de 4,6 ng/mL $\pm 14,3$ (0,1 a $95,3 \mathrm{ng} / \mathrm{mL}$ ). Foi escolhido o corte de $0,2 \mathrm{ng} / \mathrm{mL}$ correspondente à sensibilidade de $91 \%$ e especificidade de $72 \%$, de acordo com a curva ROC (Receive Operator Caracteristic Curve), para a avaliação dos níveis normais e elevados do CEA no lavado peritoneal. Trinta e quatro $(73,9 \%)$ doentes apresentaram nível de CEA no lavado peritoneal maior que $0,2 \mathrm{ng} / \mathrm{mL}$ e em $12(26,1 \%)$ enfermos, o nível do marcador CEA no lavado peritoneal foi igual ou menor que $0,2 \mathrm{ng} / \mathrm{mL}$. Houve correlação positiva entre o nível do CEA sérico e no lavado peritoneal $(\mathrm{p}=0,001)$.

A média do nível do CA 19-9 no lavado peritoneal foi de 11,1 \pm 13,7 U /mL (0,1 a 70,6 U/mL) nos doentes com carcinoma gástrico. Foi escolhido o corte de 2,2 U/mL correspondente à sensibilidade de $69 \%$ e especificidade de $38,9 \%$, de acordo com a curva ROC para a avaliação dos níveis normais e elevados do CA 19-9 no lavado peritoneal. Trinta e um $(67,4 \%)$ doentes apresentaram nível de CA 19-9 no lavado peritoneal maior que 2,01 U/mL e em 15 (32,6\%) enfermos, o nível do marcador CA 19-9 no lavado peritoneal foi igual ou menor que $2,01 \mathrm{U} / \mathrm{mL}$. Houve correlação positiva entre o nível sérico e no lavado peritoneal do CA 19-9 ( $\mathrm{p}<0,001)$.

Nos doentes com carcinoma gástrico houve correlação positiva entre os níveis séricos e no lavado peritoneal do CEA ( $p<0,001)$ e do CA19-9 ( $\mathrm{p}<0,001)$. Na análise de regressão logística múltipla, os níveis séricos do CEA nos doentes com carcinoma gástrico foram significantes $(p=0,03)$ em relação aos doentes do grupo controle.

A média do número de linfonodos extirpados dos 46 doentes com carcinoma gástrico foi de $31,9 \pm 10,4$ (10 a 54) linfonodos por peça operatória

Houve acometimento pelo carcinoma gástrico dos linfonodos extirpados em 30 (65,2\%) doentes. Em outros 16 (34,8\%) enfermos, os linfonodos da peça operatória estavam livres de acometimento neoplásico quando analisados pela técnica de estudo histopatológico da hematoxilina-eosina. Nos doentes com linfonodos infiltrados pela neoplasia, o valor médio do CEA sérico foi de 4,1 \pm 6 (0,4 a 25) ng/mL e o valor médio do CEA no lavado peritoneal foi de $6,3 \pm 17,6$ 
$(0,1$ a 95,3$) \mathrm{ng} / \mathrm{mL}$. Não houve diferença significativa $(\mathrm{p}=0,19)$ entre os níveis do CEA sérico e no lavado peritoneal com o acometimento linfonodal pelo carcinoma gástrico (Tabela 2). Nos doentes sem acometimento linfonodal, o valor médio do CEA sérico foi de 2,7 \pm 3 $(0,2$ a 12,3$) \mathrm{ng} / \mathrm{mL}$ e foi significantemente $(\mathrm{p}=0,03)$ maior do que o valor médio do CEA no lavado peritoneal que foi de $1,5 \pm 2,2$ $(0,1$ a 6) ng/mL (Tabela 2). Na comparação entre os doentes com e sem linfonodos comprometidos pelo carcinoma gástrico, os níveis de CEA sérico e no lavado peritoneal não apresentaram diferença significante ( $\mathrm{p}=0,62 \mathrm{e} \mathrm{p}=0,13$, respectivamente).

Nos doentes com linfonodos infiltrados pela neoplasia, o valor médio do CA 19-9 sérico foi de 19,7 $\pm 25 \mathrm{U} / \mathrm{mL}(0,1$ a $94,4 \mathrm{U} / \mathrm{mL})$ e o valor médio do CA 19-9 no lavado peritoneal foi de 14,1 \pm 15,6 U/mL $(0,3$ a 70,6 U/mL), não havendo diferença significante $(\mathrm{p}=0,43)$ entre esses valores (Tabela 2). Nos doentes sem linfonodos infiltrados pela neoplasia, o valor médio do CA 19-9 sérico foi de 13,4 \pm 24,6 U/mL (0,2 a 101,3 U/mL) e o valor médio do CA 19-9 no lavado peritoneal foi de 5,4 \pm 6,6 U/mL (0,1 a 19,8 U/mL) (Tabela 2). Nos doentes sem acometimento linfonodal, o valor médio do CA 19-9 sérico foi de $13,4 \pm 24,5 \mathrm{U} / \mathrm{mL}(0,2$ a 101,3 U/mL) e o valor médio do CA 19-9 no lavado peritoneal foi de 5,4 \pm 6,7 U/mL $(0,1$ a 19,8 U/mL) (Tabela 2). Os valores séricos do CA 19-9 foram significantemente $(\mathrm{p}=0,03)$ maiores do que os do lavado peritoneal nos doentes sem infiltração neoplásica pelo carcinoma gástrico (Tabela 2). Na comparação entre os doentes com e sem linfonodos comprometidos pelo carcinoma gástrico, os níveis de CA 19-9 no lavado peritoneal foram significantemente $(p=0,03)$ maiores do que os do sangue periférico.

\section{Discussão}

Embora a cirurgia com intenção curativa e ampla dissecção linfonodal seja realizada de rotina nos doentes com carcinoma gástrico, a recidiva tumoral ainda é freqüente nos doentes com câncer gástrico ${ }^{1-2,22}$. A metástase peritoneal é a mais freqüente causa de recidiva no carcinoma gástrico, e está associada a baixos índices de sobrevivência ${ }^{10,23}$. A maioria dos casos de câncer gástrico no Brasil se apresenta como doença avançada, sendo o câncer gástrico precoce encontrado em menos de $16 \%$ dos casos. Além disso, $60 \%$ dos casos de câncer gástrico avançado estão associados à metástase linfonodal ${ }^{24-27}$.

Realizou-se a determinação no lavado peritoneal dos níveis dos marcadores tumorais CEA e CA 19-9 ao término do procedimento operatório, pois é descrito que a manipulação da neoplasia e a reali- zação da linfadenectomia nas operações curativas poderiam facilitar o acesso dos marcadores à cavidade abdominal propiciando níveis mais representativos dessas substâncias ${ }^{16-17,19}$.

$\mathrm{Na}$ presente casuística observou-se que o valor sérico do CEA e CA19-9 foi significativamente mais elevado nos doentes com estádios mais avançados em relação aos estádios iniciais, sugerindo que elevações do nível sérico do CEA e CA19-9 indicariam um pior prognóstico. O desvio-padrão elevado das amostras de marcadores pode ser devido a ampla margem de variação dos valores normais dos marcadores utilizados nesse estudo, bem como à variabilidade das apresentações clínicas e a utilização de testes não paramétricos. Segundo Tachibana et al. ${ }^{28}$, os níveis séricos do CEA e CA19-9 elevados podem ser utilizados como um fator prognóstico independente. Dosagens elevadas dos níveis séricos do CEA e CA19-9 préoperatórios são úteis no prognóstico, e na identificação de metástases linfonodais e hepáticas?

Houve nesse estudo correlação positiva entre o nível de CEA sérico e do nível do CEA no lavado peritoneal $(\mathrm{p}<0,001)$. A produção do CEA pela neoplasia primária ou por metástases possivelmente presentes no organismo pode ter influência no nível peritoneal do CEA por intermédio da circulação sistêmica ${ }^{16-17,19}$.

Na comparação entre os doentes com e sem linfonodos comprometidos pelo carcinoma gástrico, os níveis de CEA sérico e no lavado peritoneal não apresentaram diferença significante. Esses resultados podem sugerir que os linfonodos infiltrados pelo carcinoma gástrico não constituem importante tecido produtor de CEA, deixando de elevar o nível do marcador no lavado peritoneal. Também Guadagni et $a l .{ }^{6}$ não observaram correlação entre o status do linfonodo e os níveis séricos do CEA. Por outro lado, níveis significativamente elevados de CEA sérico em doentes com metástases em linfonodos foram documentados em outros estudos ${ }^{10,28-31}$. Koga et al. ${ }^{9}$ constataram que, com o aumento do número de linfonodos metastáticos, o nível sérico do CEA aumentou significativamente. Esses autores sugeriram que em doentes com metástase linfática, o CEA tecidual é liberado na circulação via vasos linfáticos, evitando a depuração hepática e, portanto, elevando os índices séricos do CEA. Os resultados do presente estudo também apontaram a elevação dos níveis séricos e no lavado peritoneal do CEA quando os linfonodos estão comprometidos pelo carcinoma, embora não tenham atingido significância. Uma das razões postuladas para a disseminação peritoneal em doentes com câncer gástrico sem invasão da serosa, seria que a dissecação linfonodal durante a operação poderia abrir canais linfáticos e disseminar células

Tabela 2 - Comparação dos níveis séricos e no lavado peritoneal do CEA e CA 19-9 em relação ao acometimento linfonodal pelo carcinoma gástrico

\begin{tabular}{lcccccc}
\hline & CEA sérico & CEA no lavado & $p$ & CA 19-9 sérico & CA 19-9 no lavado & $p$ \\
\hline Linfonodos acometidos & $4,1 \pm 6 \mathrm{ng} / \mathrm{mL}$ & $6,3 \pm 17,6 \mathrm{ng} / \mathrm{mL}$ & \multirow{2}{*}{$0,19(\mathrm{NS})$} & $19,7 \pm 25 \mathrm{U} / \mathrm{mL}$ & $14,1 \pm 15,6 \mathrm{U} / \mathrm{mL}$ & $0,43(\mathrm{NS})$ \\
$\mathrm{N}=30(65,2 \%)$ & $(0,4 \mathrm{a} 25 \mathrm{ng} / \mathrm{mL})$ & $(0,1 \mathrm{a} 95,3 \mathrm{ng} / \mathrm{mL})$ & & $(0,1 \mathrm{a} 94,4 \mathrm{U} / \mathrm{mL})$ & $(0,3 \mathrm{a} 70,6 \mathrm{U} / \mathrm{mL})$ & \\
Linfonodos livres & $2,7 \pm 3 \mathrm{ng} / \mathrm{mL}$ & $1,5 \pm 2,2 \mathrm{ng} / \mathrm{mL}$ & \multirow{2}{*}{$0,08^{*}$} & $13,4 \pm 24,6 \mathrm{U} / \mathrm{mL}$ & $5,4 \pm 6,7 \mathrm{U} / \mathrm{mL}$ \\
$\mathrm{N}=16(34,8 \%)$ & $(0,2 \mathrm{a} 12,3 \mathrm{ng} / \mathrm{mL})$ & $(0,1 \mathrm{a} 6 \mathrm{ng} / \mathrm{mL})$ & & $(0,2 \mathrm{a} 101,3 \mathrm{U} / \mathrm{mL})$ & $0,1 \mathrm{a} 19,8 \mathrm{U} / \mathrm{mL}$ & $0,03^{*}$ \\
\hline
\end{tabular}

$\mathrm{N}$ : número de doentes; NS: não significante; * : significante 
neoplásicas livres na cavidade peritoneal. Outro mecanismo seria a disseminação de células neoplásicas a partir de linfonodos comprometidos pela neoplasia ${ }^{32-35}$.

Os valores séricos do CA 19-9 foram significantemente maiores do que os do lavado peritoneal nos doentes sem infiltração neoplásica dos linfonodos pelo carcinoma gástrico. Já nos doentes com linfonodos comprometidos pelo carcinoma gástrico, os níveis de CA 19-9 no lavado peritoneal foram significantemente maiores do que os do sangue periférico. Esses achados podem significar que o nível no lavado peritoneal do CA 19-9 é influenciado pelo acometimento linfonodal do carcinoma gástrico e, se isto for constatado, a sua determinação pode apresentar potencial de denunciar o envolvimento linfonodal mesmo sem evidências desse acometimento nos exames de imagem ou pelo estudo anatomopatológico. Esse fato poderia constituir valiosa informação para o estadiamento mais acurado do doente, melhor planejamento terapêutico complementar e prognóstico mais acurado, podendo precipitar a indicação de quimioterapia, na ausência de outros parâmetros indicativos para tal procedimento. Também Kodera et al. ${ }^{10}$ encontraram índice significativamente maior de metástases linfonodais nos doentes com CA 19-9 sérico elevado.

O carcinoma gástrico precoce pode revelar elevação de marcador tumoral no lavado peritoneal, sugerindo presença de rotas de penetração na parede do estômago por células tumorais sem invasão por continuidade na serosa. Canais linfáticos ou micrometástases nos linfonodos são exemplos dessas possíveis rotas. Essa idéia é apoiada parcialmente pelo fato da recidiva peritoneal ocorrer em cerca de $1 \%$ dos carcinomas gástricos precoces ${ }^{36,37}$. Tal fato sugere a presença de rotas de penetração na parede do estômago por células neoplásicas, sem que haja invasão da serosa pelo carcinoma gástrico. Canais linfáticos localizados na parede gástrica ou micrometástases nos linfonodos são exemplos dessas possíveis $\operatorname{rotas}^{38}$.

Células neoplásicas esfoliadas do tumor podem secretar CEA e CA19-9 na cavidade peritoneal. Contudo, o alto nível do CEA e do CA 19-9 no lavado peritoneal detectado em alguns doentes com carcinoma sem invasão da serosa não pode ser explicado por essa hipótese, uma vez que células neoplásicas são esfoliadas de lesões que apresentam invasão da serosa ${ }^{39}$.

Nishiyama et al..$^{39}$ relataram que os níveis peritoneais de CEA em casos avançados de carcinoma gástrico relacionaram-se estatisticamente com a profundidade da infiltração do carcinoma na parede gástrica, à presença de metástases nos linfonodos e à distância e o estádio da do- ença. Esses resultados não foram significativos para os níveis de CEA sérico. Diferenças marcantes nos níveis do CEA sérico foram observadas somente entre doentes com estadiamento $\mathrm{N} 1$ e N2 e entre M0 e M1. O presente estudo também apontou diferença entre os níveis do CEA peritoneal em relação ao diâmetro da lesão, acometimento linfonodal, invasão angiolinfática e da serosa do estômago pela neoplasia, diferenciação celular, presença de células em anel de sinete, nível de penetração do carcinoma na parede gástrica e o estadiamento mais avançado do carcinoma gástrico.

A análise do linfonodo sentinela para investigar a distribuição dos linfonodos metastáticos no carcinoma gástrico como base lógica para a realização da linfadenectomia é técnica promissora para tornar mais acurado o estadiamento da lesão, porém seus resultados ainda são controversos $^{40,41}$.

A detecção de micrometástases em linfonodos no carcinoma gástrico por imunocoloração com anticorpos anticitoqueratina pode ser útil na predição da possibilidade de recidiva, especialmente no carcinoma gástrico precoce ${ }^{42}$. Outro estudo ${ }^{43}$ mostrou que a presença de micrometástase em linfonodos no carcinoma gástrico teve impacto negativo na sobrevivência de cinco anos.

Embora a presença de níveis do CEA no lavado peritoneal possa refletir, principalmente, a presença de células malignas na cavidade peritoneal, as células do carcinoma primário ou metastático em qualquer lugar do corpo podem também contribuir para o aumento dos níveis peritonais do $\mathrm{CEA}^{31,37,39}$.

A determinação dos níveis do CEA e do CA 19-9 no lavado peritoneal pode fornecer informações mais precisas sobre a terapia adjuvante contra células neoplásicas e também uma avaliação mais pertinente desses tratamentos. O nível do CEA e do CA 19-9 no lavado peritoneal pode ser útil como indicador para a detecção de disseminação linfonodal oculta e para predizer o prognóstico do doente com carcinoma gástrico operado com intenção curativa.

Os resultados deste estudo sugerem que nos doentes com carcinoma gástrico o nível no lavado peritoneal do CA 19-9 pode sinalizar presença de infiltração linfonodal e constituir parâmetro para a indicação de tratamento adjuvante.

\section{Agradecimentos}

Rafaella Falco Bruhn recebeu bolsa de Iniciação Científica do NEPAS (Núcleo de Estudos, Pesquisa e Assessoria à Saúde da FMABC). 


\section{Referências}

1. Maehara Y, Hasuda S, Koga T, Tokunaga E, Kakeji Y, Sugimachi K. Postoperative outcome and sites of recurrence in patients following curative resection of gastric cancer. Br J Surg 2000;87(3):353-7.

2. Yoo CH, Noh SH, Shin DW, Choi SH, Min JS. Recurrence following curative resection for gastric carcinoma. Br J Surg 2000;87(2):236-42.

3. Haugstvedt TK, Vist A, Eide GE, Suöreide 0. Norwegian multicentre study of survival and prognostic factors in patients undergoing curative resection for gastric carcinoma. The Norwegian Stomach Cancer Trial. Br J Surg 1993;80(4):475-8

4. Adachi Y, Oshiro T, Mori M, Maehara Y, Sugimachi K. Prediction of early and late recurrence after curative resection for gastric carcinoma. Cancer 1996;77(12):2445-8

5. Maehara Y, Emi Y, Baba H, Adachi Y, Akazawa K, Ichiyoshi $Y$ et al. Recurrences and related characteristics of gastric cancer. $\mathrm{Br} \mathrm{J}$ Cancer 1996;74(6):975-9.

6. Guadagni S, Catarci M, Kinoshitá T, Valenti M, De Benardinis G, Carboni M. Causes of death and recurrence after surgery for early gastric cancer. World J Surg 1997;21(4):434-9.

7. Gold P, Freedman SO. Demonstration of tumor-specific antigens in human colonic carcinomata by immunological tolerance and absorption techniques. J Exp Med 1965;121:439-62.

8. Horie Y, Miura K, Matsui K, Yukimasa A, Ohi S, Hamamoto T et al. Marked elevation of plasma carcinoembryonic antigen and stomach carcinoma. Cancer 1996;77(10):1991-7.

9. Koga T, Kano T, Souda K, Oka N, Inokuchi K. The clinical usefulness of preoperative CEA determination in gastric cancer. Jpn J Surg 1987:17(5):342-7

10. Kodera Y, Yamamura Y, Torii A, Uesaka K, Hirai T, Yasui K et al. The prognostic value of preoperative serum levels of CEA and CA 19-9 in patients with gastric cancer. Am J Gastroenterol 1996;91(1):49-53.

11. Sipponen P, Lindgren J. Sialylated Lewis determinant CA 19-9 in benign and malignant gastric tissue. Acta Pathol Microbiol Immunol Scand 1986;94(5):305-11.

12. Victorzon M, Haglund C, Lundin J, Roberts PJ. A prognostic value of CA19-9 but not of CEA in patients with gastric cancer. Eur J Surg Oncol 1995;21(4):379-84.

13. Nakajima K, Ochiai T, Suzuki T, Shimada H, Hayashi H, Yasumoto A et al Impact of preoperative serum carcinoembryonic antigen, CA19-9 and alpha fetoprotein levels in gastric cancer patients. Tumor Biol 1998;19(6):464-9.

14. Mattar R, Alves de Andrade CR, DiFavero GM, Gama-Rodrigues JJ, Laudanna AA. Preoperative serum levels of CA 72-4, CEA, CA19-9, and alpha-fetoprotein in patients with gastric cancer. Rev Hosp Clin Fac Med Sao Paulo 2002;57(3):89-92

15. Tomasich FDS, Augusto VC, Luz MA, Dias LAN, Kato M. Correlação entre os marcadores tumorais CEA e CA 19-9 e a profundidade de invasão no câncer gástrico. Rev Bras Cancerol 2002;48:57-62.
16. Irinoda T, Terashima M, Takagane A, Sasaki N, Abe K, Araya M et al. Carcinoembryonic antigen level in peritoneal washing is a prognostic factor in patients with gastric cancer. Oncol Rep 1998:5(3):661-6.

17. Asao T, Fukuda T, Yazawa S, Nagamachi Y. Carcinoembryonic antigen levels in peritoneal washings can predict peritoneal recurrence after curative resection of gastric cancer. Cancer 1991;68(1):44-7.

18. Maehara $Y$, Kusumoto $T$, Takahashi I, Kakeji $Y$, Baba H, Akazawa $\mathrm{K}$ et al. Predictive value of preoperative carcinoembryonic antigen levels for the prognosis of patients with well-differentiated gastric cancer. A multivariate analysis. Oncology 1994;51(3):234-7.

19. Abe N, Watanabe T, Toda H, Machida H, Suzuki K, Masaki $T$ et al. Carcinoembryonic antigen levels in peritoneal washes: a potential prognostic marker for patients with colorectal cancer. Hepatogastroenterology 2003;50(52):1025-8

20. Japanese Gastric Cancer Association. Japanese Classification of Gastric Carcinoma - 2nd English Edition. Gastric Cancer 1998;1(1):10-24.

21. Colcher D, Hand PH, Nuti M, Schlom J. A spectrum of monoclonal antibodies reactive with human mammary tumor cells. Proc Natl Acad Sci USA1981;78(5):3199-203

22. Allgayer $\mathrm{H}$, Heiss MM, Schildberg FW. Prognostic factors in gastric cancer. Br J Surg 1997;84(12):1651-64

23. Rosenberg R, Nekarda H, Bauer P, Schenck U, Hoefler H, Siewert JR. Free peritoneal tumour cells are an independent prognostic factor in curatively resected stage IB gastric carcinoma. Br J Surg 2006;93(3):325-31.

24. Lee WJ, Lee WC, Houng SJ, Shun CT, Houng RL, Lee PH et al. Survival after resection of gastric cancer and prognostic relevance of systemic lymph node dissection: twenty years experience in Taiwan. World J Surg 1995;19(5):707-13.

25. Lourenço LG, Hamada GS. Gastric cancer in Brazil. Gastric Cancer 2001;4(2):103-5

26. Maehara Y, Kakeji Y, Koga T, Emy Y, Baba H, Akazawa K et al. Therapeutic value of lymph node dissection and the clinical outcome for patients with gastric cancer. Surgery 2002;131 (Suppl 1):S85-91.

27. Sakakura C, Takemura M, Hagiwara A, Shimomura K, Miyagawa K, Nakashima $S$ et al. Overexpression of dopa decarboxylase in peritoneal dissemination of gastric cancer and its potential as a novel marker for the detection of peritoneal micrometastases with real-time RT-PCR. Br $J$ Cancer 2004;90(3):665-71

28. Tachibana M, Takemoto Y, Nakashima Y, Kinugasa S, Kotoh T, Dahr DK et al. Serum carcinoembryonic antigen as a prognostic factor in resectable gastric cancer. J Am Coll Surg 1998;187(1):64-8.

29. Nakane Y, Okamura S, Akehira K, Boku T, Okusa T, Tanaka K et al. Correlation of preoperative carcinoembryonic antigen levels and prognosis of gastric cancer patients. Cancer 1994;73(11):2703-8.

30. Fujii S, Kitayama J, Kaisaki S, Sasaki S, Seto Y, Tominaga 0 et al. Carcinoembryonic antigem mRNA in abdominal cavity as a useful predictor 
of peritoneal recurrence of gastric cancer with serosal exposure. J Exp Clin Cancer Res 2002;21(4):547-53

31. Li JK, Zheng M, Miao CW, Zhang JH, Ding GH, Wu WS. Peritoneal lavage cytology and carcinoembryonic antigen determination in predicting peritoneal metastasis and prognosis of gastric cancer. World J Gastroenterol 2005;11(46):7374-7.

32. Maehara Y, Oshiro T, Baba H, Ohno S, Kohnoe S, Sugimachi K. Lymphatic invasion and potencial for tumor growth and metastasis in patients with gastric cancer. Surgery 1995;117(4):380-5.

33. Mandorwski S, Lourenço LG, Forones NM. CA 72-4 e CEA no soro e no lavado peritoneal de doentes com câncer gástrico. Arq Gastroenterol 2002;39(1):17-21.

34. Marutsuka T, Shimada S, Shiomori K, Hayashi N, Yagy Y, Yamane T et al. Mechanisms of peritoneal metastasis after operation for non-serosainvasive gastric carcinoma: an ultrarapid detection system for intraperitoneal free cancer cells and a prophylactic strategy for peritoneal metastasis. Clin Cancer Res 2003;9(2):678-85.

35. Ueno H, Yoshida K, Hirai T, Kono F, Kambe M, Toge T. Quantitative detection of carcinoembryonic antigen messenger RNA in the peritoneal cavity of gastric cancer patients by real-time quantitative reverse transcription polymerase chain reaction. Anticancer Res 2003;23(2c):1701-8.

36. Sano T, Sasako M, Kinoshita T, Maruyama K. Recurrence of early gastric cancer. Follow up of 1475 patients and review of the Japanese literature. Cancer 1993;72(11):3174-8.
37. Yamamoto M, Baba H, Kakeji Y, Endo K, Ikeda Y, Toh Y et al. Prognostic significance of tumor markers in peritoneal lavage in advanced gastric cancer. Oncology 2004;67(1):19-26.

38. Zhang YS, Xu J, Luo GH, Wang RC, Zhu J, Zhang XY et al. Detection of carcinoembryonic antigen mRNA in peritoneal washes from gastric cancer patients and its clinical significance. World J Gastroenterol 2006;12(9):1408-11.

39. Nishiyama M, Takashima I, Tanaka T, Yoshida K, Toge T, Nagata N et al. Carcinoenbryonic antigen levels in the peritoneal cavity: useful guide to peritoneal recurrence and prognosis for gastric cancer. World $J$ Surg1995;19(1):133-7.

40. Rino, Y, Takanashi Y, Hasuo K, Kawamoto M, Ashida A, Harada H et al. The validity of sentinel lymph node biopsy using dye technique alone in patients with gastric cancer. Hepatogastroenterology 2007;54(78):1882-6.

41. Miyashiro I, Miyoshi N, Hiratsuka M, Kishi K, Yamada T, Ohue M et al. Detection of sentinel node in gastric cancer surgery by indocyanine green fluorescence imaging: comparison with infrared imaging. Ann Surg Oncol 2008;15(6):1640-3.

42. Saito H, Osaki T, Murakami D, Sakamoto T, Kanaji S, Ohro $S$ et al. Recurrence in early gastric cancer - presence of micrometastasis in lymph node of node negative early gastric cancer patient with recurrence. Hepatogastroenterology 2007;54(74):620-4.

43. Kim JH, Park JM, Jung CW, Park SS, Kim SJ, Mok YJ et al. The significances of lymph node micrometastasis and its correlation with $\mathrm{E}$-cadherin expression in pT1-T3N0 gastric adenocarcinoma. J Surg Oncol 2008;97(2):125-30. 